\title{
İndirgenmiş Grafen Oksit ile Kaplanan Pamuk Kumaşın Elektriksel İletkenlik ve Haslık Özelliklerinin İncelenmesi
}

\author{
The Investigation of Electrical Conductivity and Color Fastness Properties of Reduced \\ Graphene Oxide Coated Cotton Fabric \\ Bekir Cenkkut GÜLTEKİN 1 (iD \\ ${ }^{1}$ Marmara Üniversitesi, Teknoloji Fakültesi, Tekstil Mühendisliği Bölümü, 34722, İstanbul/Türkiye
}

\begin{abstract}
Öz
Bu çalışmada, \%100 grafen oksit içeren pat hazırlanarak rakle kaplama makinasında pamuk kumaş üzerine kaplama işlemi gerçekleştirildi. $\mathrm{Bu}$ amaçla, grafit partiküllerden kimyasal oksidasyon yöntemiyle grafen oksit sentezlendi. Herhangi bir yardımcı kimyasal kullanılmadan hazırlanan \%100 grafen oksitten oluşan hidrosol ile kaplama işleminin ardından grafen oksitin elektriksel olarak iletken yapıya dönüşmesi amacıyla $\mathrm{C}$ vitamini ile indirgeme işlemi uygulandı. Grafen oksit ve indirgenmiş grafen oksit kaplanmış kumaşın karakterizasyonu Fourier dönüşümlü kızılötesi spektroskopisi (FTIR) ile gerçekleştirildi ve yüzey özellikleri taramalı elektron mikroskobu (SEM) ile incelendi. Elektriksel direnç, dört nokta prob tekniği ile ölçüldü. Yıkama ve sürtme haslık testleri gerçekleştirilerek indirgenmiş grafen oksit kaplı kumaşın elektriksel direnç dayanımı belirlendi. Buna göre, grafen oksit kaplanan pamuk kumaşta elektriksel direnç 4.46E+06 $\Omega / \square$ olarak elde edildi ve C vitamini ile indirgeme işlemi sonrası elektriksel direnç 2.56E+02 $\Omega / \square$ olarak ölçüldü. Yıkama sonrasında elektriksel direnç değerinde kaydadeğer bir değişim olmadığı ancak haslık testleri sonrasında bir miktar artış olduğu gözlendi. Ayrıca, indirgenmiş grafen oksit kaplı pamuk kumaşın elektromanyetik kalkanlama etkinliği de incelendi ve kumaşın katlanmasıyla kalkanlama etkinliğinin arttığı görüldü.
\end{abstract}

Anahtar kelimeler: grafen oksit, kaplama, indirgeme, elektriksel iletkenlik, pamuk kumaş.

\section{Abstract}

In this study, $100 \%$ graphene oxide containing paste were prepared and coated on cotton fabric in a knife coating machine. For this purpose, graphene oxide is synthesized from graphite by the chemical oxidation method. After the coating process of graphene oxide hydrosol which is prepared without any auxiliary chemicals, the reduction process with Vitamin $\mathrm{C}$ was applied to obtain the electrically conductive structure. The characterization of graphene oxide and reduced graphene oxide coated cotton fabric was carried out by Fourier transform infrared spectroscopy (FTIR) and the surface properties were examined with scanning electron microscopy (SEM). The electrical resistivity was measured by four point probe technique. The durability of electrical resistivity after washing and rubbing fastness tests was also determined. The electrical resistivity of graphene oxide coated cotton fabric was obtained as $4.46 \mathrm{E}+06 \Omega / \square$ and after the Vitamin $\mathrm{C}$ reduction process, the electrical resistivity was measured as $2.56 \mathrm{E}+02 \Omega / \square$. It was observed that there was no significant change in electrical resistivity after washing test while the electrical resistivity increased after the rubbing fastness tests. Additionally, the electromagnetic shielding effectiveness of reduced graphene oxide coated cotton fabric was tested and it was seen that the electromagnetic shielding effectiveness was increased with the plying of fabric.

Key words: graphene oxide, coating, reduction, electrical conductivity, cotton fabric.

\section{GİRIS}

Grafen, tek tabaka karbon atomlarının 2 boyutlu balpeteği yapısında düzenlenmesiyle oluşmaktadır ve diğer tüm boyutlardaki grafitik malzemelerinin temel yapıtaşıdır. Grafen, eşsiz yapısı ve mükemmel elektronik, optik, termal ve mekanik özellikleri sebebiyle birçok konvansiyonel 3 boyutlu malzemeden farklılık göstermekte ve çok çeşitli alanlarda gelişmiş malzemelerin üretilmesinde oldukça dikkat çekmektedir [1-5]. Grafenin konvansiyonel tekstillerle birleştirilmesiyle fonksiyonel tekstillerin geliştirilmesi önemli araştırma konuları haline gelmiştir. Grafen içerikli tekstillerin gerilim sensörleri [6], süperkapasitörler [7], enerji depolama [8] gibi elektriksel uygulamalarda oldukça umut verici olduğu görülmüștür. Ayrıca, tekstillerin sahip olduğu esneklik, hafiflik, düşük maliyet gibi özelliklerinden dolayı grafen esaslı giyilebilir elektriksel iletken tekstillerin geliştirilmesi son yıllarda önem kazanmıştır [9-12]. Elektriksel iletken tekstiller sağlık, askeri, giyilebilir elektronikler ve akıllı tekstiller gibi çeşitli alanlara kullanılmaktadır. Ayrıca, halı, otomobil koltukları gibi endüstriyel ve konvansiyonel alanlarda ısıtma elemanı olarak da kullanılmaktadır [13,14]. Grafen, yüksek taşıyıcı hareket yeteneği, mekanik dayanıklılığı, çevresel kararlılığı ve düşük maliyetli üretilebilirliği sayesinde iletken katkı maddesi, mürekkep ve kaplamalarda 
kullanım için birçok gereksinimi karşılama potansiyeline sahiptir. Ancak grafende fonksiyonel grupların bulunmaması kullanımını kısıtlamaktadır. Grafenin fonksiyonelleştirilmiş türevi olan grafen oksitin yüzeyinde oldukça fazla miktarlarda hidrofilik fonksiyonel grup bulunmaktadır [15-17]. Grafen oksitin sulu dispersiyonunun halihazırda herhangi bir polimerik ya da yüzey aktif stabilizör kullanımına gerek olmadan karboksil ve hidroksil grupların varlığıyla oldukça kolay bir şekilde hazırlanabildiği görülmüştür. $\mathrm{Bu}$ avantaj, elektriksel olarak iletken tekstillerin geliştirilmesinde, tıpkı bitim işlemlerinde olduğu gibi daldırma, kaplama veya boyama prosesi şeklinde grafenin direk olarak uygulanabilirliğini mümkün kılmıştır [1, 15]. Grafen oksit tabakaları, kumaşta bulunan fonksiyonel gruplar ve grafen oksitteki fonksiyonel gruplar arasındaki çekim kuvvetlerinin etkisiyle kumaş yüzeyine adsorbe olurlar [18]. Ancak grafen oksit elektriksel olarak yalıtkan olduğundan uygulama sonrasında indirgenerek elektriksel olarak iletken olan indirgenmiş grafen oksite dönüştürülmesi gerekmektedir [19]. Tekstil yüzeylerinde grafen oksitin indirgeme prosesi genellikle farklı kimyasal indirgeme maddelerinin kullanıldığı kimyasal indirgeme ile ve inert atmosfer veya kimyasal indirgeyici gaz ortamında yüksek sıcaklıkta termal indirgeme işlemleri ile gerçekleştirilmektedir [16]. Kimyasal indirgeme işleminde çeşitli özelliklerde indirgeme maddeleri kullanılmaktadır. Bunlara örnek olarak toksik ve insan sağlığına ve çevreye oldukça zararlı hidrazin, hidrokinon, sodyum borohidrit verilebilir. Son yıllarda grafen oksitin çevre dostu indirgenmesinde yaygın olarak kullanılan malzeme ise askorbik asittir (C Vitamini) [20-24]. Birçok tekstil malzemesi arasında pamuk kumaş en yaygın olarak kullanılan malzemedir. Pamuğun kimyasal yapısında bulunan hidroksil gruplardan dolayı pamuk kumaş kolaylıkla modifiye edilebilir ve diğer aktif malzemelerle etkileşimi artırılabilir [15]. Elektriksel iletken pamuk kumaş üretiminde indirgenmiş grafen oksit kullanımıyla ilgili birtakım çalışmalar bulunmaktadır. $\mathrm{Bu}$ çalışmaların çoğunda daldırma yöntemiyle kaplama prosesi yaygın olarak uygulanmıştır. Ancak, bu yöntemde kumaş üzerindeki grafen oksit miktarını artırmak için çoklu tekrarların yapılması gerektiğinden, bu proses büyük ölçekli üretimler için uygun değildir [1, 3, 15, 25-29].

$\mathrm{Bu}$ çalışmada, \%100 grafen oksit içeren pat hazırlanarak rakle kaplama makinasında pamuk kumaş üzerine kaplama işlemi gerçekleştirilmiştir. $\mathrm{Bu}$ pat içerisinde herhangi bir yardımcı kimyasal ve bağlayıcı madde kullanılmamıştır. \%100 grafen oksit kaplanan pamuk kumaşın elektriksel olarak iletken yapıya dönüşmesi amacıyla $\mathrm{C}$ vitamini ile indirgeme işlemi uygulanmıştır. Grafen oksit ve indirgenmiş grafen oksit kaplanmış kumaşın karakterizasyonu Fourier dönüşümlü kızılötesi spektroskopisi (FTIR) ve taramalı elektron mikroskobu (SEM) ile gerçekleştirilmiştir. Elektriksel direnç, dört nokta prob tekniği ile ölçülmüştür. Yıkama ve sürtme haslık testleri gerçekleştirilerek indirgenmiş grafen oksit kaplı kumaşın elektriksel direnç dayanımı belirlenmiştir.

\section{MATERYAL VE METOT}

\subsection{Malzemeler}

Grafit partiküller Sigma Aldrich firmasında temin edilmiştir. Hidrojen peroksit $\left(\mathrm{H}_{2} \mathrm{O}_{2}, \% 35\right)$, sülfürik asit $\left(\mathrm{H}_{2} \mathrm{SO}_{4}, \% 95-98\right)$, fosforik asit $\left(\mathrm{H}_{3} \mathrm{PO}_{4}\right)$, potasyum permanganat $\left(\mathrm{KMnO}_{4}\right)$ and hidroklorik asit $(\mathrm{HCl}, \% 37)$ Merck firmasından temin edilmiştir. Tüm çalışma boyunca destile su kullanılmıştır. Çalışmada \%100 pamuk, atkı sıklığ1 18 tel/cm ve çözgü sıklığ 36 tel/cm olan bezayağı dokuma kumaş kullanılmıştır.

\subsection{Grafen oksit sentezi}

Grafen oksit, grafit partiküllerden geliştirilmiş Hummer yöntemi ile sentezlenmiştir. Kisaca, 9:1 oranında $\mathrm{H}_{2} \mathrm{SO}_{4} / \mathrm{H}_{3} \mathrm{PO}_{4}(360: 40 \mathrm{~mL})$ karışımına grafit partikülleri ( $3 \mathrm{~g}$ ) ilave edilerek manyetik karıştırıcıda buz banyosunda karıştırılmıştır. Ardından, $\mathrm{KMnO}_{4}(18$ g) eklenmiş ve tamamen çözündükten sonra karışımın Sıcaklığı $50^{\circ} \mathrm{C}$ 'ye çıkarılmış ve 12 saat karıştırılmıştır. Reaksiyon sicaklığı oda sicaklığına $\left(25^{\circ} \mathrm{C}\right)$ geldikten sonra buz (400 ml) üzerine dökülmüştür ve tamamen erime gerçekleşip karışım homojen bir hale geldiğinde \%30'luk $\mathrm{H}_{2} \mathrm{O}_{2}(6 \mathrm{~mL})$ ile reaksiyon sonlandırılmıştır (Şekil 1). Elde edilen süspansiyon 8000 rpm'de 30'ar dk süre ile önce $1 \mathrm{M} \mathrm{HCl} \mathrm{çözeltisi,} \mathrm{sonra} 200 \mathrm{ml}$ etanol (x2) ve son olarak destile su ile $\mathrm{pH}$ 4-5 olana dek yıkanmıştır. Son olarak elde edilen katı ürün etüvde $60^{\circ} \mathrm{C}$ 'de kurutulmuştur.

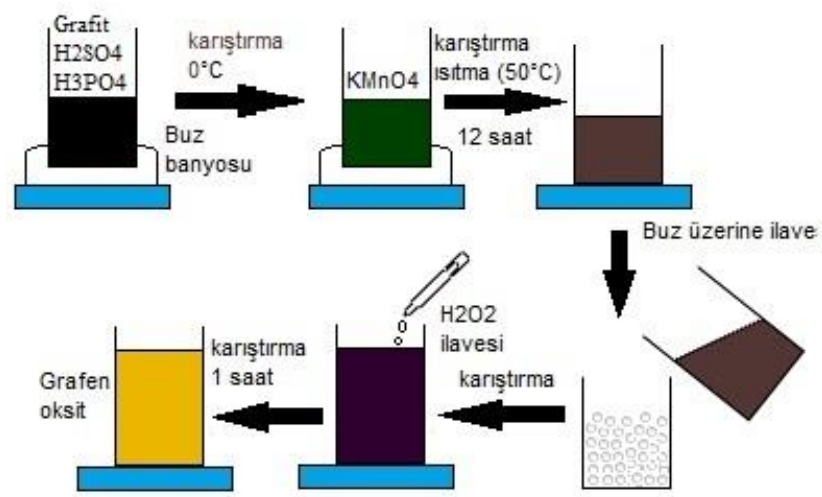

Şekil 1. Grafen oksit sentezinin şematik gösterimi

\subsection{Kaplama uygulaması ve indirgeme işlemi}

Kaplama işlemi için sentezlenen grafen oksitten 20 $\mathrm{mg} / \mathrm{ml}$ konsantrasyonda hidrosol hazırlanmıştır. Hazırlanan hidrosol içerisine yardımcı kimyasal ve bağlayıcı katılmamıştır. Elde edilen hidrosol viskositesi oda sicaklığında $\left(25^{\circ} \mathrm{C}\right) \mathrm{s} 04$ mil ile $50 \mathrm{rpm}$ hızda 964 cP (Brookfield DV-E Viscometer) olarak bulunmuştur. Pamuk dokuma kumaş kaplama makinesine numune tutucu iğnelere yerleştirilmiş ve ardından grafen oksit pat kumaşın üzerine dökülmüş ve otomatik raklenin hareketi ile kaplama işlemi gerçekleştirilmiştir (Şekil 2). Ardından kumaş $120^{\circ} \mathrm{C}$ 'de $10 \mathrm{dk}$ fikse edilmiştir. 
Elde edilen grafen oksit kaplı kumaşın indirgeme işlemi 50:1 (L:G) banyo oranında 0.1 M C vitamini sulu çözeltisinde $95^{\circ} \mathrm{C}$ 'de $90 \mathrm{dk}$ süre ile gerçekleştirilmiştir. Ardından kumaş destile su ile yıkanmış ve reaksiyon kalıntıları uzaklaştırılmıştır. Son olarak, indirgenmiş grafen oksit kaplı pamuk kumaş etüvde $90^{\circ} \mathrm{C}$ 'de $30 \mathrm{dk}$ kurutulmuştur.

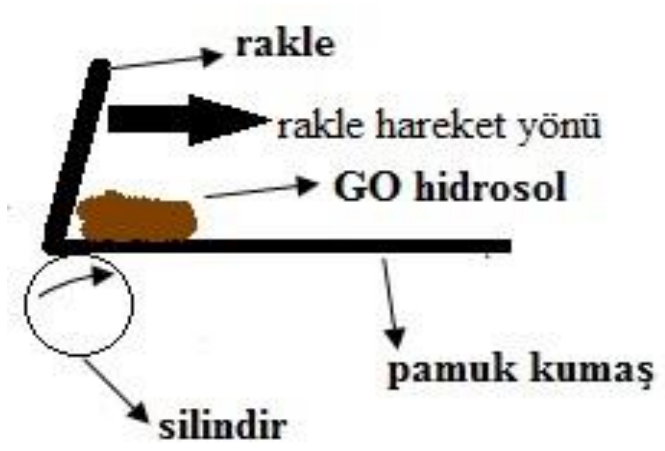

Şekil 2. Silindir üzeri rakle kaplama uygulamasının şematik görünümü

\subsection{Karakterizasyon}

Taramalı elektron mikroskobu (FE-SEM, FEI Sirion) GO ile kaplanan pamuk kumaşın yüzey morfolojisinin belirlenmesinde kullanılmıştır. GO ile kaplama sonrasında ve indirgeme işlemi sonrası ve indirgenmiş numunenin yıkama sonrası SEM analizi gerçekleştirilmiştir. Fourier dönüşümlü kızılötesi spektroskopisi (ATR-FTIR, Perkin Elmer Spectrum Two) $650-4000 \mathrm{~cm}^{-1}$ frekans aralığında numunelerin kimyasal yapılarının analizinde kullanılmıştır. Numunelerin elektriksel direnci 4-nokta uç (Keithley 2450 Sourcemeter, Everbeing Int'l Corp) ile ölçülmüştür. Kaplama kalınlık ölçümü Mitutoyo kalınlık ölçme cihazı ile gerçekleştirilmiştir. Her bir numune en az $5 \mathrm{kez}$ ölçülmüş ve ortalama sonuç dikkate alınmıştır. Kaplanan kumaşların mikroskop görüntüleri 1şık mikroskopu (Olympus, SZ-PT, SZ60) ile elde edilmiştir. Yıkamaya karşı renk haslığı testi ISO 105-C06 standardına göre uygulanmıştır.
Sonuçların değerlendirilmesinde gri skala (1 en kötü- 5 en iyi) kullanılmıştır. Sürtünmeye karşı renk haslığı testi ISO 105-X12 standardına göre uygulanmıştır. Elektromanyetik kalkanlama etkinliği, ASTM D493510 düzlemsel materyaller için koaksiyel transmisyon hattı yöntemi standardına göre test edilmiştir. Burada, numuneyi tutmak için kalkanlama etkinliği test aparatı (Electro-Metrics, Inc., model EM-2107A) ve elektromanyetik sinyal üreten ve geri dönüşü ölçen network analizör (Rohde\&Schwarz ZVL-Network Analyzer) kullanılmıştır.

\section{BULGULAR VE TARTIŞMA}

\subsection{SEM analizi}

GO kaplama, indirgeme ve yıkama işlemi sonrasında pamuk kumaşın yüzey özellikleri taramalı elektron mikroskobu ile incelenmiştir. Şekil 3 (a-c)'de GO kaplanan pamuk kumaşın farklı büyütmelerdeki görüntülerinden anlaşılacağı üzere pamuk kumaş yüzeyi GO ile homojen bir şekilde kaplanmıştır. Kumaştaki ipliklerinin üzerinin tamamen GO ile örtüldüğü ve kumaş yapısındaki boşlukların GO ile dolduğu görülmektedir. Şekil 3(b ve c)'de kumaş üzerinde GO yapısının kıvrımlı ve buruşuk bir formda olduğu anlaşılmaktadır. C vitamini ile indirgeme işlemi sonrasında pamuk kumaşa ait görüntüler şekil 3(d-f)'de verilmiştir. Buradan, indirgeme işleminden sonra kumaş üzerinde indirgenmiş GO tabakaların bulunduğu ve kaplamanın homojenliğinin bozulmadan kaldığ görülmektedir. Şekil 3f'de indirgeme işlemi ile GO tabakalardaki oksijen içerikli fonksiyonel grupların yok olması sonucu indirgenmiş grafen oksitin daha kıvrımlı ve buruşuk görüntüsünün olmadığı ve daha kırılgan bir formda olduğu söylenebilir. İndirgenmiş GO kaplı pamuk kumaşın yıkama işlemi sonrası görüntüsü şekil 3(g-1)'da verilmiştir. Yıkama işlemi sonrasında indirgenmiş GO kaplamanın pamuk kumaş üzerinde kaldığ 1 ancak kaplamanın homojenliğinin yer yer bozulduğu görülmektedir. 

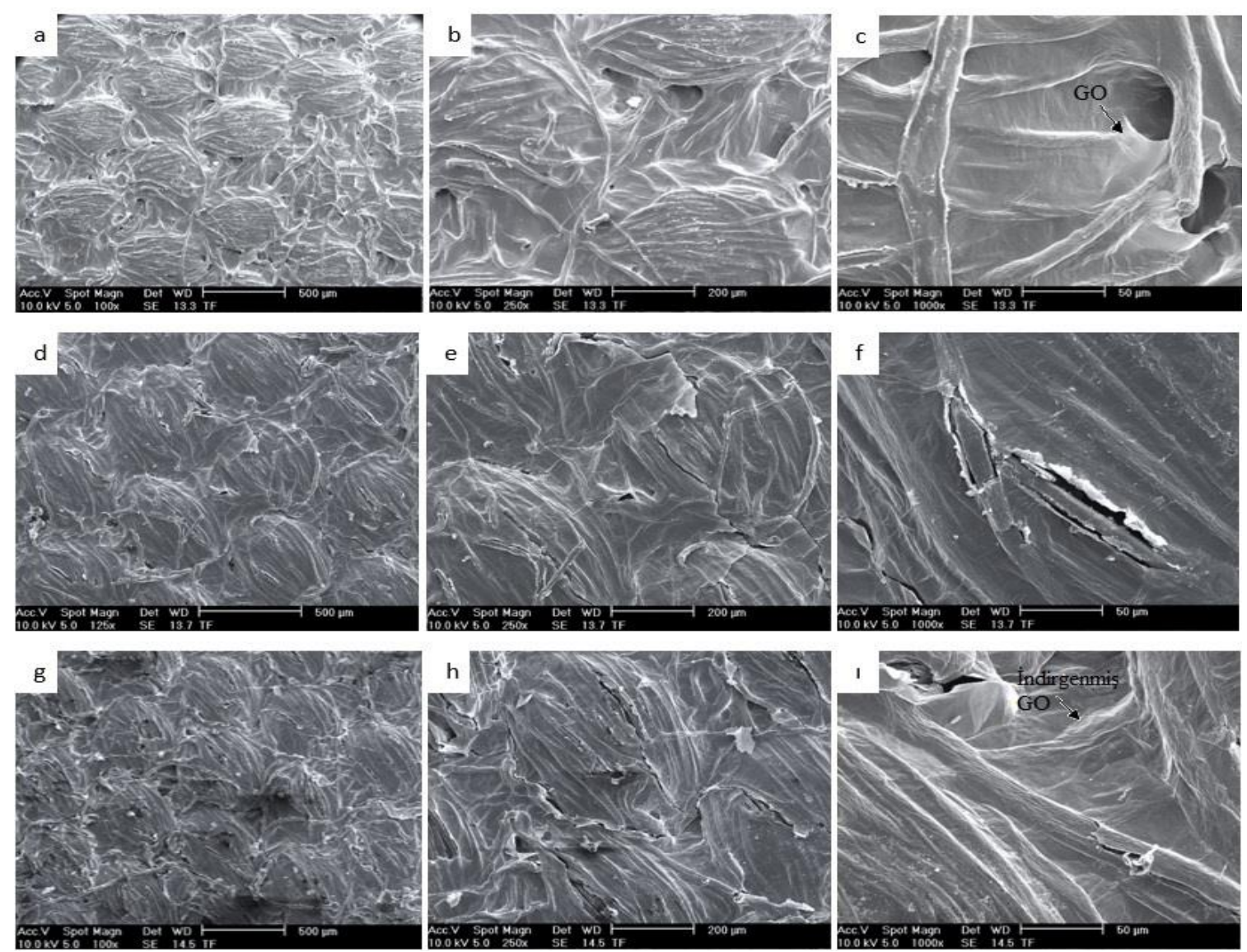

Şekil 3. Numunelere ait SEM görüntüleri (a-c) GO kaplanmış pamuk kumaş, (d-f) indirgenmiş GO kaplanmış pamuk kumaş, (g-1) yıkama sonrası indirgenmiş GO kaplanmış pamuk kumaş.

\subsection{FTIR analizi}

Şekil 4'te pamuk kumaşa, GO kaplanan ve indirgeme işlemi uygulanan kumaşlara ait FTIR spektrumu 400$4000 \mathrm{~cm}^{-1}$ aralığında verilmiştir. Ölçümler, kumaşın kaplanmış yüzeyinde gerçekleştirilmiştir. Burada, pamuk kumaşa ait karakteristik pikler belirgin bir şekilde görülmektedir. GO kaplama işleminin ardından yeni piklerin oluştuğu net bir şekilde söylenebilir. 2923 ve $2851 \mathrm{~cm}^{-1}$, de simetrik ve asimetrik $\mathrm{CH}_{2}$ moleküler esneme titreşimlerine ve $1741 \mathrm{~cm}^{-1}$ 'de karboksil gruplarının ve karbonil içeren grupların artmasıyla $\mathrm{C}=\mathrm{O}$ esnemesine ait pik oluşumu görülmektedir. 1621 $\mathrm{cm}^{-1}$ 'de oluşan pik ise GO'da bulunan su moleküllerine ait $-\mathrm{OH}$ gruplarının bükülme ve esneme titreşimlerini göstermektedir. Bir diğer belirgin değişim ise 3300$3400 \mathrm{~cm}^{-1}$ deki hidroksil (-OH) bandının genişlemesidir. Tüm bu değişimler GO partiküllerinin kumaş yüzeyine tutunduğunu göstermektedir [30, 31]. İndirgeme işleminden sonra ise elde edilen spektrumda belirgin değişikliklerin olduğu görülmektedir. GO'ya ait karakteristik piklerin yok olduğu açıça görülmektedir. Buradan, indirgeme işleminin başarılı bir şekilde gerçekleştiği ve oksijen içerikli grupların uzaklaştırıldığ

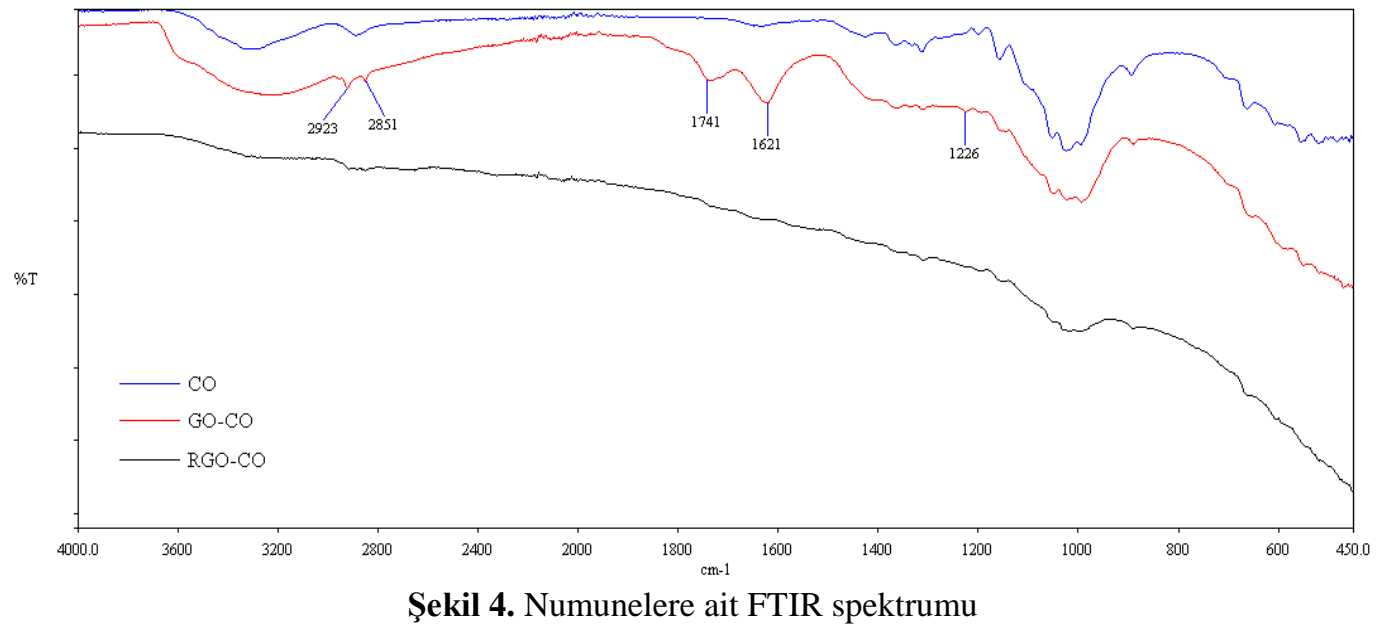




\subsection{Yüzey morfolojisi ve kaplama kalınlığı}

Şekil 5'te GO kaplanmış ve indirgenmiş GO kaplanmış pamuk kumaşa ait 1şık mikroskop görüntüleri verilmiştir. Şekil 5 (a) grafen oksit ve (c) indirgenmiş grafen oksit kaplı pamuk kumaşın yüzey görüntülerine ait iken, (b) grafen oksit ve (d) indirgenmiş grafen oksit kaplı pamuk kumaşın kesit görüntülerini vermektedir. Açıkça görülmektedir ki, GO kaplama işlemi kumaş yüzeyinde başarı ile gerçekleştirilmiş ve kaplama rengi kahverengi olarak görülmektedir. GO’nun elektriksel olarak iletken olan indirgenmiş GO'ya dönüştüğünün tespit edilmesinde ilk ve en belirgin yöntem görsel olarak değerlendirmedir. İndirgeme işlemi ile oksijen içerikli fonksiyonel grupların uzaklaştırılarak kaplama renginin siyah-metalik gri olarak elde edildiği ve kaplamanın homojen bir şekilde kumaş üzerinde olduğu görülmektedir.

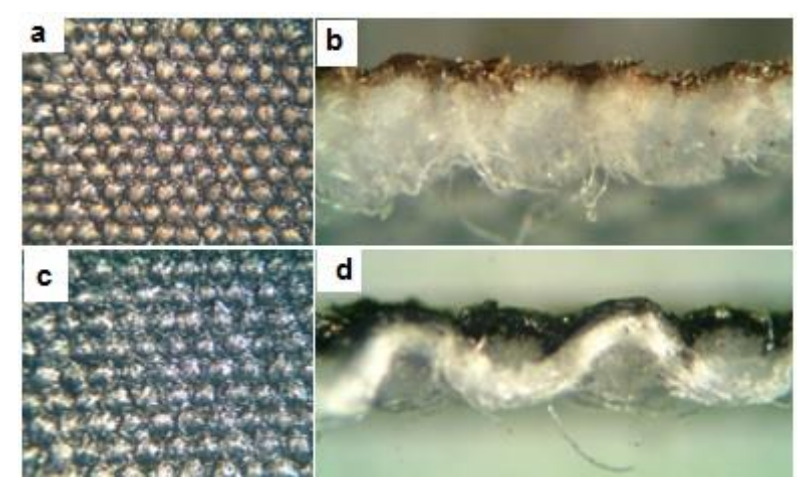

Şekil 5. GO (a, b) ve indirgenmiş GO kaplı pamuk kumaşın $(\mathrm{c}, \mathrm{d})$ yüzey ve kesit mikroskop görüntüleri

Şekil 6'da GO kaplanmış ve indirgenmiş GO kaplanmış pamuk kumaşa ait kaplama kalınlığ verilmiştir. Kaplama kalınlık ölçümü, kaplanmış kumaşın kalınlığından işlem görmemiş kumaşın kalınlığının çıkarılması ile elde edilmiştir. Şekil 6'da, GO ve indirgenmiş GO kaplamaların kalınlıklarının 12 $\mu \mathrm{m}$ olduğu görülmektedir. İndirgeme işleminden sonra kaplama kalınlığının değişmediği açıkça görülmektedir. Ancak, yıkama işleminden sonra indirgenmiş GO kaplama kalınlığında bir miktar azalma meydana gelmiştir. Kaplama kalınlığı yıkama işleminden sonra $10 \mu \mathrm{m}$ 'ye düşmüştür. Y1kama işlemi ile kumaş üzerindeki indirgenmiş GO miktarında azalma olduğu ve kumaşa tam olarak tutunamayan indirgenmiş GO partiküllerin yıkama esnasındaki mekanik etkiyle uzaklaştığı söylenebilir.

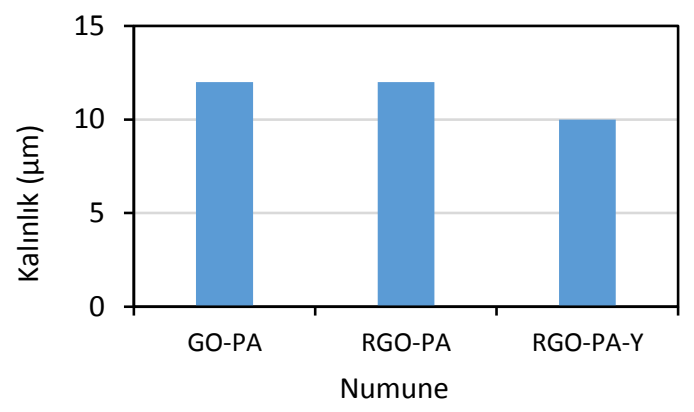

Şekil 6. Kaplama kalınlığ 1

\subsection{Elektriksel direnç ölçümü}

GO kaplanmış ve indirgenmiş GO kaplanmış pamuk kumaşa ait elektriksel direnç ölçüm sonuçları Tablo 1 'de verilmiştir. Buradan görüldüğü gibi GO kaplanan kumaşın elektriksel direnci oldukça yüksek bir değere $(4.46 \mathrm{E}+06 \Omega / \square)$ sahiptir. C vitamini ile indirgeme işleminden sonra yapılan ölçümde elektriksel direnç değerinde belirgin bir düşüş olduğu açıkça ifade edilmektedir. $2.56 \mathrm{E}+02 \Omega / \square$ olarak elde edilen bu değer ile indirgenmiş GO kaplı pamuk kumaşın elektriksel olarak iletken olduğu söylenebilir.

Tablo 1. GO kaplanan ve indirgeme işlemi uygulanan kumaşın elektriksel direnç sonuçları

\begin{tabular}{|l|l|}
\hline Numune & Elektriksel direnç $(\Omega / \square)$ \\
\hline GO-PA & $4.46 \mathrm{E}+06$ \\
\hline RGO-PA & $2.56 \mathrm{E}+02$ \\
\hline
\end{tabular}

\subsection{Yıkamaya karşı renk haslığı testi}

İndirgenmiş GO kaplı pamuk kumaşın yıkamaya karşı renk haslığı testine ait sonuçlar Tablo 2'de verilmiştir. İndirgenmiş GO kaplı pamuk kumaşın yıkamaya karşı renk haslığının gri skala değerlendirmesinde en yüksek değerde olduğu görülmektedir. Y1kama sonrası kaplamada herhangi bir renk değişimi olmadığı ve kaplanmış kumaşın referans kumaşı lekelemesinin de gri skala değerlendirmesinde en iyi değere sahip olduğu açıkça ifade edilmektedir.

Tablo 2. İndirgenmiş GO kaplanan pamuk kumaşın yıkamaya karşı renk haslığının değerlendirmesi

\begin{tabular}{|c|c|c|c|c|c|c|c|}
\hline \multirow[b]{3}{*}{ Numune } & \multirow{2}{*}{\multicolumn{6}{|c|}{ Lekeleme }} & \multirow{3}{*}{$\begin{array}{l}\text { Yıkamaya } \\
\text { karşı renk } \\
\text { haslığı }\end{array}$} \\
\hline & & & & & & & \\
\hline & Yün & Akrilik & Poliester & Poliamid & Pamuk & Asetat & \\
\hline RGO-PA & 5 & 5 & 5 & 5 & 5 & 5 & 5 \\
\hline
\end{tabular}

\subsection{Sürtünmeye karşı renk haslığı testi} İndirgenmiş GO kaplı pamuk kumaşın sürtünmeye karşı renk haslığ 1 testine ait sonuçlar Tablo 3'te verilmiştir. Buna göre, indirgenmiş GO kaplı pamuk kumaşın atkı ve çözgü yönlerindeki yaş sürtme test sonucunun gri skalada değerlendirmesinde en düşük değerlere sahip olduğu açıkça görülmektedir. Bununla birlikte, kuru sürtme test sonucunun gri skaladaki değerlendirmesinin orta seviyede olduğu söylenebilir. 
Tablo 3. İndirgenmiş GO kaplanan pamuk kumaşın sürtünmeye karşı renk haslığının değerlendirmesi

\begin{tabular}{|l|l|l|l|l|} 
& \multicolumn{3}{c}{ Yaş Sürtme } & \multicolumn{2}{c}{ Kuru Sürtme } \\
Numune & Atkı & Çözgü & Atkı & Çözgü \\
\hline RGO-PA & $1 / 2$ & $1 / 2$ & $2 / 3$ & $2 / 3$
\end{tabular}

\subsection{Haslık testleri sonrası elektriksel direnc}

İndirgenmiş GO kaplanan pamuk kumaşın yıkama ve sürtme testleri sonrasında elektriksel direnç ölçüm sonuçları Tablo 4'te verilmiştir. Açıkça görülmektedir ki, sürtme ve yıkama testleri sonrasında indirgenmiş GO kaplı pamuk kumaşın elektriksel direncinde artış meydana gelmiştir. İndirgeme sonrasında ölçülen elektriksel direnç değeri $2.56 \mathrm{E}+02 \Omega / \square$ iken, yas ve kuru sürtme sonrası bu değer, sirasıyla, en yüksek $5.39 \mathrm{E}+04 \Omega / \square$ ve $4.34 \mathrm{E}+03 \Omega / \square$ olarak elde edilmiştir. Ancak yıkama testi sonrasında elektriksel dirençte meydana gelen artış dikkate alınmayacak seviyede düşüktür.

Tablo 4. Sürtme ve yıkama testleri sonrasında indirgenmiş GO kaplı numunelerin elektriksel direnç sonuçları

\begin{tabular}{|l|l|l|l|l|l|}
\hline & \multicolumn{5}{c}{ Klektriksel direnç $(\Omega / \square)$} \\
\hline Numune & Atkı & Çözgü & Atki Sürtme & Çözgü & Yıkama \\
\hline RGO-PA & $3.05 \mathrm{E}+04$ & $5.39 \mathrm{E}+04$ & $4.34 \mathrm{E}+03$ & $4.06 \mathrm{E}+03$ & $5.19 \mathrm{E}+02$ \\
\hline
\end{tabular}

Yıkama testi öncesi ve sonrasında indirgenmiş GO kaplı pamuk kumaşın sarı LED lambaları yaktığı görseller Şekil 7'de verilmiştir. Buradan anlaşılacağ üzere, indirgenmiş GO kaplama sarı LED lambaları yakacak yeterli elektriksel iletkenlik değerine sahiptir. Buna ilave olarak, yıkama işlemi sonrasında da kaplamanın elektriksel iletkenliğinde değişiminin olmadığı yine sarı LED lambanın yanmasıyla da desteklenmektedir.

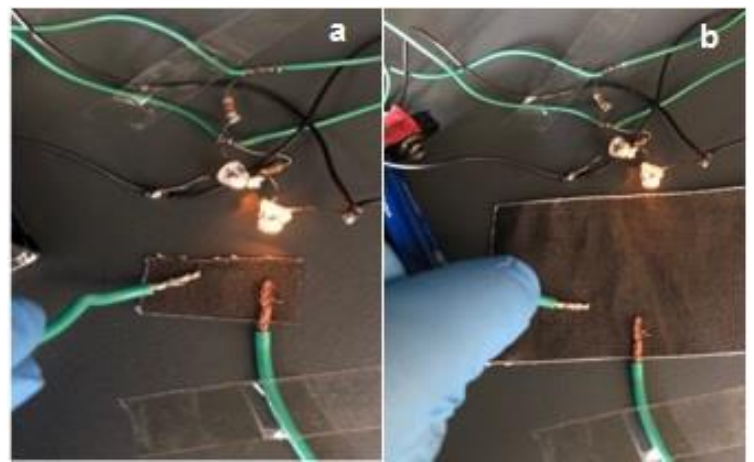

Şekil 7. Yıkama testi öncesi (a) ve sonrasında (b) indirgenmiş GO kaplı pamuk kumaşta sarı LED'in yanması

\section{8. İndirgenmiş GO kaplı pamuk kumaşın elektromanyetik kalkanlama etkinliği}

İndirgenmiş GO kaplanan pamuk kumaşın elektromanyetik kalkanlama etkinliği ölçüm sonuçları Şekil 8'de verilmiştir. Elektromanyetik kalkanlama etkinliği, indirgenmiş grafen oksit kaplı pamuk kumaşın tek kat, iki kat ve dört kat şeklinde katlanmasıyla ölçülmüştür. Buradan anlaşılacağı üzere, indirgenmiş GO kaplı pamuk kumaşın elektromanyetik kalkanlama etkinliği kumaşın katlanma sayısının artmasıyla doğru orantılı olarak artmaktadır. Kumaşın tek kat olarak elektromanyetik kalkanlama etkinliği değeri en yüksek $2.35 \mathrm{~dB}$ olarak $2205 \mathrm{MHz}$ frekansta elde edilirken, iki kat olarak en yüksek değer $4.56 \mathrm{~dB}$, dört kat olarak $7.18 \mathrm{~dB}$ olarak yine aynı frekansta elde edilmiştir.

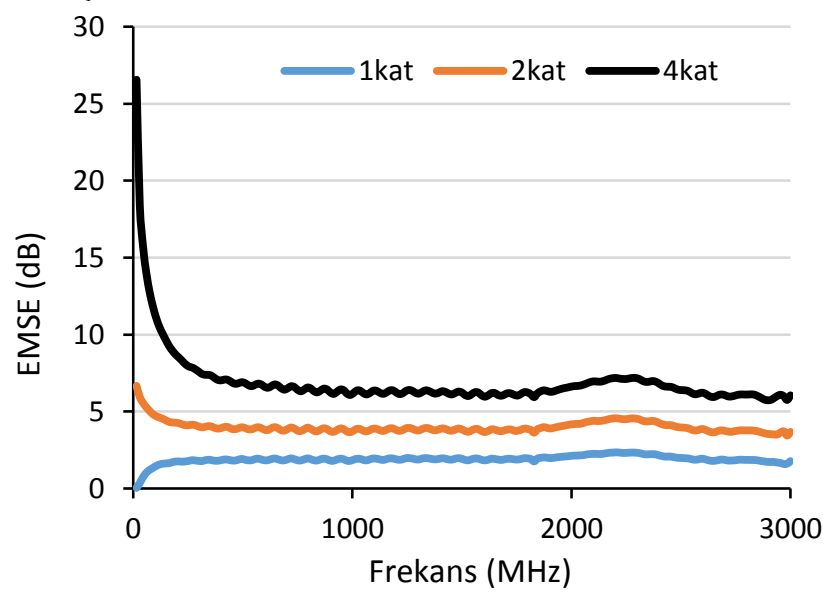

Şekil 8. İndirgenmiş GO kaplanan pamuk kumaşın elektromanyetik kalkanlama etkinliği

\section{SONUCLAR}

$\mathrm{Bu}$ çalışmada, herhangi bir yardımcı kimyasal kullanılmadan \%100 grafen oksit içerikli hidrosol hazırlanarak pamuk kumaş üzerine rakle ile kaplama yöntemiyle uygulanmıştır. Ardından $\mathrm{C}$ vitamini ile indirgeme işlemi gerçekleştirilerek yapılan kaplamanın elektriksel olarak iletken hale gelmesi sağlanmıştır. FTIR ve SEM analizleri ile grafen oksitin kumaş yüzeyine başarılı bir şekilde kaplandığı net bir şekilde görülmüştür. Ayrıca $\mathrm{C}$ vitamini ile indirgeme işlemi sonrasında yapıdaki oksijen içerikli fonksiyonel grupların uzaklaştırıldığı da bu analizlerde açıç̧a ortaya konmuştur. İndirgeme işleminin başarılı bir şekilde gerçekleştirildiğinin bir diğer önemli kanıtı da elektriksel direnç değerindeki belirgin değişimdir. İndirgenmiş GO kaplı pamuk kumaşın yıkamaya ve sürtünmeye karșı renk haslığı testleri sonucunda kaplamanın yıkama sonrasında daha kalıcı olduğu ve elektriksel direncin değişmediği, özellikle yaş sürtmeye karşı renk haslığının en kötü olduğu ve elektriksel direnç artışının en fazla olduğu ortaya konmuștur. 
Ayrıca, elektromanyetik kalkanlama etkinliği ölçüm sonucunda, indirgenmiş GO kaplı pamuk kumaşın katlama sayısının artmasıyla doğru orantılı olarak kalkanlama etkinliğinin arttığı net olarak belirtilmiştir.

\section{KAYNAKLAR}

[1] Shateri-Khalilabad, M. ve Yazdanshenas, M. E. (2013). Fabricating electroconductive cotton textiles using graphene. Carbohydr Polym., 96(1), 190-195.

[2] Tissera, N.D., Wijesena, R. N., Perera, J. R., De Silva, K. M. N. ve Amaratunge, G. A. J. (2015). Hydrophobic cotton textile surfaces using an amphiphilic graphene oxide (GO) coating. Appl Surf Sci, 324, 455-463.

[3] Hu, X., Tian, M., Qu, L., Zhu, S., Han, G. (2015). Multifunctional cotton fabrics with graphene/polyurethane coatings with far-infrared emission, electrical conductivity, and ultravioletblocking properties. Carbon, 95, 625-633.

[4] Lu, Z., Mao, C. ve Zhang, H. (2015). Highly conductive graphene-coated silk fabricated via a repeated coating-reduction approach. J Mater Chem $C$, 3(17), 4265-4268.

[5] Zhao, J., Deng, B., Lv, M., Li, J., Zhang, Y., Jiang, H., Peng, C., Li, J., Shi, J., Huang, Q., Fan, C. (2013). Graphene oxide-based antibacterial cotton fabrics. $A d v$ Healthc Mater. 2(9), 1259-66.

[6] Wang, D., Li, D., Zhao, M., Xu, Y., Wei, Q. (2018). Multifunctional wearable smart device based on conductive reduced graphene oxide/polyester fabric. Appl Surf Sci. 454, 218-226.

[7] Shao, F., Bian, S. W., Zhu, Q., Guo, M. X., Liu, S., Peng, Y. H. (2016). Fabrication of Polyaniline /Graphene /Polyester Textile Electrode Materials for Flexible Supercapacitors with High Capacitance and Cycling Stability. Chem Asian J. 11(13), 1906-12.

[8] Ramadoss, A., Saravanakumar, B. ve Kim, S. J. (2015). Thermally reduced graphene oxide-coated fabrics for flexible supercapacitors and self-powered systems. Nano Energy. 15, 587-597.

[9] Ji, Y., Li, Y., Chen, G., Xing, T. (2017). Fireresistant and highly electrically conductive silk fabrics fabricated with reduced graphene oxide via drycoating. Mater Design. 133, 528-535.

[10] Gültekin, N. D. ve Usta, İ. (2015). Investigation of Thermal and Electrical Conductivity Properties of Carbon Black Coated Cotton Fabrics. Marmara University Journal of Science. 27(3).

[11] Babaahmadi, V., Montazer, M. ve Gao, W. (2018). Surface modification of PET fabric through in-situ reduction and cross-linking of graphene oxide: Towards developing durable conductive fabric coatings. Colloid Surface A. 545, 16-25.

[12] Cai, G., Yang, M., Xu, Z., Liu, J., Tang, B., Wang, X. (2017). Flexible and wearable strain sensing fabrics. Chem Eng J. 325, 396-403.

[13] Kongahge, D., Foroughi, J., Gambhir, S., Spinks, G. M., Wallace, G. G. (2016). Fabrication of a graphene coated nonwoven textile for industrial applications. RSC Adv. 6(77), 73203-73209.
[14] Berendjchi, A., Khajavi, R., Yousefi, A. A., Yazdanshenas, M. E. (2016). Improved continuity of reduced graphene oxide on polyester fabric by use of polypyrrole to achieve a highly electro-conductive and flexible substrate. Appl Surf Sci. 363, 264-272.

[15] Ren, J., Wang, C., Zhang, X., Carey, T., Chen, K., Yin, Y., Torrisi, F. (2017). Environmentally-friendly conductive cotton fabric as flexible strain sensor based on hot press reduced graphene oxide. Carbon. 111, 622-630.

[16] Javed, K., Galib, C. M. A., Yang, F., Chen, C. M., Wang, C. (2014). A new approach to fabricate graphene electro-conductive networks on natural fibers by ultraviolet curing method. Synthetic Met. 193, 41-47.

[17] Fugetsu, B., Sano, E., Yu, H., Mori, K., Tanaka, T. (2010). Graphene oxide as dyestuffs for the creation of electrically conductive fabrics. Carbon. 48(12), 33403345.

[18] Molina, J., Fernández, J., Fernandes, M., Souto, A. P., Esteves, M. F., Bonastre, J., Cases, F. (2015). Plasma treatment of polyester fabrics to increase the adhesion of reduced graphene oxide. Synthetic Met. 202, 110-122.

[19] Molina, J., Fernández, J., del Río, A., Bonastre, J., Cases, F. (2013). Chemical and electrochemical study of fabrics coated with reduced graphene oxide. Appl Surf Sci. 279, 46-54.

[20] Li, C., Zhuang, Z., Jin, X., Chen, Z. (2017). A facile and green preparation of reduced graphene oxide using Eucalyptus leaf extract. Appl Surf Sci. 422, 469474.

[21] Thakur, S. ve Karak, N. (2015). Alternative methods and nature-based reagents for the reduction of graphene oxide: A review. Carbon. 94, 224-242.

[22] Zhang, J., Yang, H., Shen, G., Cheng, P., Zhang, J., Guo, S. (2010). Reduction of graphene oxide via Lascorbic acid. Chem Commun (Camb). 46(7), 1112-4. [23] Pei, S. ve Cheng, H. M. (2012). The reduction of graphene oxide. Carbon. 50(9), 3210-3228.

[24] Fernandez-Merino, M.J., Guardia, L., Paredes, J., Villar-Rodil, S., Solis-Fernandez, P., Martınez-Alonso, A., Tasco, J. M. D. (2010). Vitamin C Is an Ideal Substitute for Hydrazine in the Reduction of Graphene Oxide Suspensions. J Phys Chem C. 114, 6426-6432.

[25] Cai, G., Xu, Z., Yang, M., Tang, B., Wang, X. (2017). Functionalization of cotton fabrics through thermal reduction of graphene oxide. Appl Surf Sci. 393, 441-448.

[26] Karimi, L., Yazdanshenas, M. E., Khajavi, R., Rashidi, A., Mirjalili, M. (2015). Functional finishing of cotton fabrics using graphene oxide nanosheets decorated with titanium dioxide nanoparticles. $J$ Text $I$. 107(9), 1122-1134.

[27] Krishnamoorthy, K., Navaneethaiyer, U., Mohan, R., Lee, J., Kim, S. J. (2011). Graphene oxide nanostructures modified multifunctional cotton fabrics. Applied Nanoscience. 2(2), 119-126.

[28] Sahito, I.A., Sun, K. C., Arbab, A. A., Qadir, M. B., Jeong, S. H. (2015). Graphene coated cotton fabric as textile structured counter electrode for DSSC. 
Electrochim Acta. 173, 164-171.

[29] Shateri-Khalilabad, M. ve Yazdanshenas, M. E. (2013). Preparation of superhydrophobic electroconductive graphene-coated cotton cellulose. Cellulose. 20(2), 963-972.

[30] Sahito, I.A., Sun, K. C., Arbab, A. A., Qadir, M. B., Jeong, S. H. (2015). Integrating high electrical conductivity and photocatalytic activity in cotton fabric by cationizing for enriched coating of negatively charged graphene oxide. Carbohydr Polym. 130, 299306.

[31] Aslam, M., Kalyar, M. A. ve Raza, Z. A. (2016). Synthesis and structural characterization of separate graphene oxide and reduced graphene oxide nanosheets. Mater Res Express. 3(10). 